\title{
Dual employment protection and (lack of) on-the-job training: PIAAC evidence for Spain and other European countries
}

\author{
Antonio Cabrales ${ }^{1}$ • Juan J. Dolado ${ }^{2}$. \\ Ricardo Mora $^{3}$
}

Received: 21 January 2017 / Accepted: 6 November 2017 / Published online: 16 November 2017 (C) The Author(s) 2017. This article is an open access publication

\begin{abstract}
Using micro data from the Programme for the International Assessment of Adult Competencies (PIAAC), we first document how having a temporary contract in Spain is associated to lower levels of on-the-job training (OJT). Next, we find that this OJT gap is positively correlated with gaps in the literacy and numeracy scores achieved by these two types of workers in the PIAAC study. Although we choose Spain as a case study of a dual labor market, we also provide cross-country evidence showing that OJT gaps are lower in those European labor markets where dualism is less entrenched than in those where it is more extended.
\end{abstract}

Keywords Dual labor market · On-the-job training $\cdot$ Cognitive skills · Severance pay

\begin{abstract}
We are grateful to the Editor (Nezih Guner), two anonymous referees, Andrea Bassanini, Roman Fossati, Andrea Ichino, Greg Jolivet, Stepan Jurajda and Helene Turon, as well as participants in the CAGE conference on "Education, Human Capital and Labor Market Outcomes" (Venice), ESSLE 2014 (Ammersee) and seminars at Bristol, IMT-Lucca and Padua for useful comments and suggestions that improved the paper. We also wish to thank Nicolas Escribano for excellent research assistance. Financial support from the Spanish Ministerio de Economía y Competitividad (Grants ECO2016-78652,

ECO2015-65204-P, AND MDM 2014-0431) and from Consejería de Educación, Juventud y Deportes de la Comunidad de Madrid (S2015/HUM-3444) are gratefully acknowledged.
\end{abstract}

Antonio Cabrales

a.cabrales@ucl.ac.uk

Juan J. Dolado

juan.dolado@eui.eu

Ricardo Mora

ricmora@eco.uc3m.es

1 University College London, London, UK

2 European University Institute, Florence, Italy

3 Universidad Carlos III Madrid, Getafe (Madrid), Spain 
JEL Classification C14 · C52 - D24 · J24

\section{Introduction}

This paper looks at whether the gap between the amount of on-the-job training (OJT hereafter) employers provide to permanent workers (those holding an openended/indefinite contract) and temporary workers (those holding a fixed-term contract) is larger in labor markets with highly discontinuous severance pay schemes than in less segmented ones. One plausible mechanism leading to this differential in training relies on the larger turnover rate experienced by temporary workers because of the much less stringent employment protection legislation (EPL henceforth; in particular mandated severance pay) they enjoy relative to permanent workers. Whenever wage rigidity prevents firms neutralizing severance payments (i.e., a transfer from employers to workers), this gap in EPL rules makes firms more prone to use temporary contracts in sequence and less so to convert these contracts into permanent contracts. As a result of the greater job churn of temporary workers, employers do not find it profitable to invest in their OJT. Conversely, the higher job stability implied by the much higher EPL enjoyed by permanent workers makes firms more eager to invest in their training.

As a byproduct of exploring the previous channel, we are also interested in documenting whether gaps in OJT due to dual EPL are positively correlated with differences in workers' cognitive skills. To the extent that training at the workplace helps accumulating these skills, dualism in the labor market may not only hinder temporary workers' specific human capital but may also lead to a negative "value-added" effect (i.e., in addition to the skills achieved through education and other observable characteristics) on their accumulation of general human capital. ${ }^{1}$

Both are issues of considerable importance for policy in Europe, especially in Southern Mediterranean countries which have been badly hit by the crisis. A wellknown example is Spain, often considered as an epitome of a highly segmented labor market (OECD 2014). For this reason we devote the first part of the paper to carefully illustrate how the mechanism at play works for this country. Yet, because the explored channel is general in nature, further empirical evidence is provided in the second part of the paper on, first, how differences in the degree of EPL gap affect OJT in a large set of European countries and, second, how differences in OJT lead to differences in general human capital skills.

Regarding our case study, the rate of temporary work (i.e., the share of employees under temporary contracts) soared in Spain from $15 \%$ just before the radical labor market reform of 1984 to $35.4 \%$ in the mid-nineties (see, e.g., Dolado et al. 2002; De la Rica et al. 2008). ${ }^{2}$ Since then, around $90 \%$ of newly signed contracts each year

\footnotetext{
1 According to Acemoglu and Pischke (1999), when labor market frictions compress the wage structure (for example, through a highly unionized workforce), it might be the case that employer-sponsored training includes financing of investment in general human capital. Thus, OJT might affect not only specific but also general human capital.

2 The 1984 labor market reform in Spain allowed the indiscriminate use of temporary contracts (with very low termination costs) for any regular productive activity while keeping unchanged the rigid EPL of permanent contracts inherited from industrial relations during the Franco regime.
} 


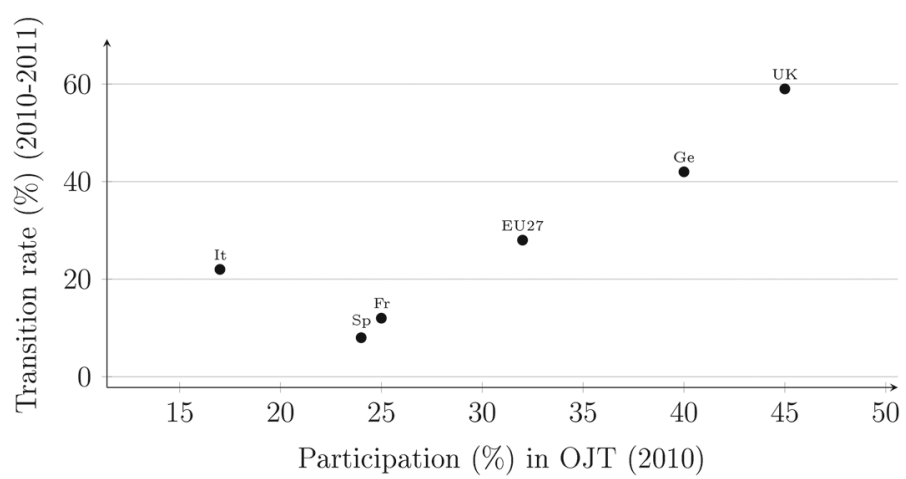

Fig. 1 Temp-to-perm transition rates and on-the-job training in several European countries. Note: The sources for transition and participation rates are Eichhorst (2013) and Fifth European Working Conditions Survey (2010), respectively

have been temporary ones, out of which one quarter last for less than one week and their average duration hardly reaches around two months. The average temp-to-perm conversion rate has fallen from $12 \%$ in the nineties and first half of the 2000s to about $7 \%$ in 2014 (see Amuedo-Dorantes 2001; Güell and Petrongolo 2007). Following a long sequence of partial labor market reforms after 1984, the rate of temporary work stabilized around $30 \%$ at the turn of the new century (see Bentolila et al. 2012). More recently, the mass destruction of temporary jobs during the Great Recession and the sovereign debt crisis lowered the rate to $25 \%$, which has gone up to $27 \%$ over the subsequent recovery and still remains as one of the highest rates in Europe and among OECD member countries.

As regards workers' involvement in OJT schemes, the participation rate in Spain increased from $10 \%$ in the early nineties to $24 \%$ in 2010 , but still remains at the bottom of the EU, together with Italy. It is 8 percentage points below the EU average, and between 20 to 30 points lower than in Scandinavian countries and the UK (see The European Commission 2014). As further motivation of our argument, Fig. 1 displays the transition rates from temporary to permanent contracts (vertical axis, in percent) in 2011, as a measure of segmentation in labor markets (see Eichhorst 2013), and the fraction of employees participating in OJT schemes (horizontal axis, in percent) in the five largest EU countries and the EU average as of 2010. This evidence suggests that in countries where temporary contracts become a springboard to more stable jobs, workers' participation in OJT schemes tends to be higher.

Returning to our argument above, lower OJT attached to temporary contracts might be one of the main reasons for why these contracts are often considered to be dead ends in dual labor markets while they become stepping stones in other labor markets where the EPL gap is smaller or even absent (see Booth et al. 2002; Autor 2001). By contrast, stringent EPL for permanent contracts implies that OJT is higher for this type of workers. Thus, both features put together imply that a dual labor market structure has distributional consequences for OJT.

To document the role of OJT in the mechanism described above, we use detailed information for Spain and other twelve European countries drawn from the first wave 
(2013) of the Survey of Adult Skills, the main output of the Programme for the International Assessment of Adult Competencies, PIAAC. This survey provides a harmonized dataset for a large number of countries on the availability of OJT at individual level (both at the extensive and intensive margins), as well as a wide array of individuallevel demographics and job characteristics, including type of labor contract. Further, the availability of PIAAC scores on workers' literacy and numeracy competencies allows us also to explore whether OJT affects workers' proficiency conditional on predictors of previously acquired skills, including educational attainment or family background.

A note of caution is due before summarizing our main empirical findings. Our approach relies on comparing workers with similar observable characteristics, except type of labor contract (our treatment). We argue that selection on un-observables is not likely to play a major role in our setup. There are two reasons to think so. First, it is the case that PIAAC contains a much wider array of individual and job characteristics than other datasets which have been used in previous studies about the effects of temporary contracts on labor market outcomes. For example, PIAAC includes variables like the worker's motivation and her/his use of reading and numerical skills at the workplace, as well as detailed educational achievements and family background covariates; these are often considered to be among the standard confounding factors leading to biases in the estimation of causal effects by standard regression analysis. ${ }^{3}$ Hence, in a rich dataset as ours, the set of potentially confounding unobservables is bound to be small. Secondly, as argued in the next section, it is also the case that, at least for Spain, a comparison of non-experimental and quasi-experimental estimates of the returns to temporary work is bound to yield minor differences. This may possibly reflect that, in a country where more than $90 \%$ of entry jobs are temporary, selection issues into type of contract are not so crucial. Nevertheless, we refrain throughout the paper from readily admitting a causal interpretation of our results.

Despite the limitations imposed by the use of our cross-sectional dataset, our interpretation of the main empirical findings obtained from the Spanish PIAAC sample is that they are rather supportive of the mechanism stressed above. First, we find a substantially negative and statistically significant relationship between holding a temporary contract and the amount of workplace training. Secondly, we document that the less OJT individuals received amount, the worse their test scores (especially as regards numeracy), on top of those predicted by their individual characteristics. Foremost, we provide similar evidence for a pool of 13 European countries for which a novel proxy of dual EPL is constructed. We find that the above-mentioned results are stronger for countries with segmented labor markets than for those with more unified labor markets.

The rest of the paper is organized as follows. Section 2 provides a brief overview of the related literature on this topic. Section 3 describes the PIAAC database, provides descriptive statistics of main variables of interest, and motivates the empirical strategy. Section 4 presents the main empirical results for our illustrative case study, Spain. Section 5 reports further cross-country evidence for our sample of European countries.

\footnotetext{
3 See Dearden et al. (2002) for similar arguments in a study of the effects of school quality on students' labor market outcomes.
} 
Finally, Sect. 6 draws some brief conclusions. An "Appendix" develops a simple theoretical model that guides our empirical approach.

\section{Related literature review}

From a European cross-country perspective, the closest studies to ours are Arulampalam et al. (2004) and Bassanini et al. (2007) who use panel data from the European Community House Panel (waves 1995-2001) to deal with the effects of temporary and permanent contracts on OJT. Their focus is mostly on the extensive margin of OJT since the European Community House Panel has rather limited information on training duration and intensity. ${ }^{4}$ In general, they find that temporary workers receive less training but the results are heterogeneous and not too precisely estimated. More recently, a comprehensive empirical analysis based on PIAAC has also been undertaken in the OECD Employment Outlook (OECD 2014), using pooled data for a large set of OECD countries. The main finding is that being on a temporary contract reduces the probability of receiving employer-sponsored training by $14 \%$. However, their interpretation of this negative effect relies on the fixed-term nature of temporary contracts, which reduces the returns to training, without considering the possibility that firms may have of retaining temporary workers by upgrading their contracts to permanent contracts, like in Spain.

As regards the relationship between dualism and the incidence of occupational training in Spain, it is worth highlighting the papers by Alba-Ramirez (1994) and De la Rica et al. (2008). These authors document that firms invest less in training temporary workers given their high turnover rates. However, they do not examine how the amount of training responds to changes in the EPL gap. This result is also in line with the findings by Arulampalam et al. (2004) that Spain is one of the European countries where being on a fixed-term contract leads to lower training. In line with this approach, Dolado et al. (2016) present a model where the decisions of employers and workers interact in a dual labor market akin to the Spanish one. Their main result is that, when the EPL gap is large, not only employers find it unprofitable to invest in training temporary workers but also that these workers would respond to the lower and more uncertain promotion prospects by exerting lower effort. This leads to self-fulfilling prophecies where employers do not invest in workers, expecting that they will not exert enough effort, and workers fulfill these expectations by rationally anticipating very low promotion prospects. Using a large panel dataset of manufacturing firms, and focusing on major EPL reforms in Spain, they show that increases in the EPL gap lead to lower temp-to-perm conversion rates and that the latter imply lower productivity growth at the firm level. Yet, due to lack of information on training and workers' effort in their dataset, they are not able to explore the kind of research questions that we address here.

In addition, Garda (2012) has analyzed the size of wage losses experienced by those workers who have been displaced to other firms as a result of having been subject to a collective dismissal in their previous firm. If firms provide a higher level of specific

\footnotetext{
4 See Section 2.6 in Bassanini et al. (2007) for a detailed discussion on this issue.
} 
training to workers under permanent contracts than to those under temporary contracts, the loss of this type of human capital will be larger for the first type of workers than for the second. Therefore, we would expect to find higher wage losses among workers with permanent contracts. Using the Social Security records and controlling for job tenure, occupational industry and other covariates, the results confirm that permanent workers subject to collective dismissals suffer higher and more permanent wage cuts than those with temporary contracts.

Lastly, as anticipated in the Introduction, we end this section with a brief discussion on how results derived from non-experimental and quasi-experimental studies compare as regards the effects of temporary work on, say, earnings or employment stability. Most of the literature on the labor market impact of temporary contracts has relied on regression analysis and other non-experimental identification techniques. Yet, to our knowledge, there are only two quasi-experimental studies, one by Autor and Houseman (2010) on temporary-help jobs in the US and another by García-Pérez et al. (2016) on temporary contracts in Spain. On the one hand, Autor and Houseman (2010) uses data from a city of Detroit's welfare-to-work program where workers are randomly assigned to contractors with different placement rates into temporary-help and directhire jobs. The results in OLS and IV models (using random contractor assignments as instrumental variables) differ: while OLS estimates show that temporary-help jobs increase earnings and employment of welfare clients relative to nonparticipants in the program, no statistically significant effects are obtained from IV. It is argued that this difference may arise because OLS captures effects for average clients while IV does so for marginal ones (i.e., those less able to find jobs through family contacts and friends). However, unlike ours, their dataset does not contain information on family background or work experience since labor market entry, which could help control for omitted network effects. On the other hand, García-Pérez et al. (2016) uses Social Security records in Spain to assess the long-term impact of temporary contracts deregulation on the two above-mentioned outcomes, following the 1984 EPL reform. Focusing on male school dropouts at age 16, they use a cohort regression discontinuity design comparing young workers who entered the labor market just before and right after the reform, under the assumption that differences in entry dates are fairly random. In contrast to Autor and Houseman (2010), the estimates have the same sign and their magnitude is in the same ballpark as other studies which either use OLS regressions with a large set of controls (see e.g., Amuedo-Dorantes and Serrano-Padial 2007; Güell and Petrongolo 2007) or dynamic simulation techniques (Aguirregabiria and Alonso-Borrego 2014).

\section{Data and empirical strategy}

\subsection{Data and main variables of interest}

The population of interest is defined by those individuals aged 16-65 who participated in PIAAC and had the status of employees in the private sector at the time of the survey. As regards Spain, out of the 6055 individuals who fully responded to the questionnaires, about 2500 were employees. 
Our main control variable, temporary, is a dummy variable that takes value 1 when the contract is a temporary one (defined in PIAAC as having a fixed-term contract, temporary employment with an employment agency, or some kind of training contract) and value 0 when the employee holds a permanent contract. In a robustness check for our main results, we will also consider a narrower definition of temporary contracts which excludes training contracts.

To empirically evaluate how holding a temporary contract is associated with a lower propensity to be involved in training activities, we consider two proxies of specific human capital accumulation at the workplace which are available in the PIAAC data. First, we use an indicator variable, $D^{O J T}$, which takes the value 1 if the worker claims to have attended a training session organized in the workplace or provided by their supervisors or colleagues in the past 12 months, and 0 otherwise. Thus, this variable captures the extensive margin of $\mathrm{OJT}^{5}$

To capture the intensive margin of OJT, we use an additional outcome variable which measures the number of training activities attended by the worker during the past 12 months, denoted as $n^{O J T}$. All training tasks that are interrelated, even if they have taken place on different days, count as a single activity. The essential feature of each activity is that it should be designed "to facilitate the adaptation of personnel to a particular set of new competences". Therefore, this variable captures the intensity of investment in new competencies regardless of their level of difficulty or the time that has been devoted to each one of them. ${ }^{6}$

To analyze how differences in training lead to differences in general human capital we exploit two measurements of general cognitive skills reported in PIAAC, namely, test scores achieved on literacy and numeracy tests. More specifically, we use the literacy and numeracy ten plausible values attributed from the responses to exercises which are part of the survey. The literacy test plausible values measure the ability to understand and use texts (written or in a digital format) in different contexts, while the numeracy test values measure the use, application, interpretation and communication of mathematical information and ideas.

\subsection{Empirical strategy}

The main hypothesis and empirical strategy can be motivated by a search and matching model for a dual labor market in the spirit of Berton and Garibaldi (2012), who rationalize the co-existence of permanent and temporary workers in steady-state. A key

\footnotetext{
5 These training sessions are characterized "by planned periods of training, instruction or practical experience, using the normal methods of work." For example, they include "training or instruction courses organized by the directors, managers or colleagues to help the respondent to do their job better or to familiarize them with their new tasks."

6 PIAAC also provides a subjective measurement that aims to reflect the intensity with which the worker acquires new skills in the job. Respondents indicate the frequency with which their job involves learning new skills. Besides the problem of interpretation often encountered with such subjective statements, this variable does not have enough variation to be really informative: over $90 \%$ of respondents reply that their job involves learning new skills "at least once a month." For these reasons, we discard it in our set of OJT outcomes.
} 
assumption in their model is that workers under temporary contracts can be dismissed at will while those under permanent contracts can never be fired. The reason why both types of contract co-exist is twofold. On the one hand, from a labor demand perspective, firms face a trade-off between ex-ante speed of job filling rates (higher for permanent contracts) and ex-post flexibility of dismissal rates (higher for temporary contracts). On the other hand, from a labor supply perspective, workers are attracted by the higher job security given by permanent contracts but are exposed to a lower job filling rate when they search for them. As a result, the model features a natural sorting of firms and workers into permanent and temporary jobs, reproducing the main features of a dual labor market. After an adverse productivity shock, these authors show that firms are more likely to train workers under permanent contracts to return to higher productivity levels. Intuitively, if the costs of training are sufficiently large, the firm would always prefer to train a permanent worker who cannot be fired than a temporary worker who can be dismissed at will. Thus, an interesting issue is whether a similar result holds when allowing for limited severance pay for permanent workers and the possibility of upgrading temporary contracts to permanent contracts within the same job_as in Cahuc and Postel-Vinay (2002) and Bentolila et al. (2012). In the "Appendix" we present a model along these lines where it is shown that, for sufficiently low temp-to-perm conversion rates, a higher severance pay gap decreases OJT for temporary workers whereas it increases OJT for permanent workers. Hence, our main testable hypothesis is that increases in EPL gaps will lead to higher OJT gaps between permanent and temporary workers.

At the empirical level it important to notice that workers with a high level of motivation to perform well in the job could influence their employer to obtain a permanent contract and, simultaneously, choose to participate intensively in OJT activities. In that case, the observed positive correlation between having a permanent contract and participation in training activities would be the result of systematic differences in workers' motivation levels and not of differences in firing costs. As long as type of contract is endogenous, cross-country correlations between EPL and OJT gaps by type of contract cannot be given a causal interpretation.

The ideal experiment for testing the main hypotheses of this paper would be one where workers are randomly assigned to temporary and permanent contracts (see Autor and Houseman 2010, for the US), or where comparable labor markets (with the same structure of jobs and workers) are assigned to different regimes of dual EPL (see García-Pérez et al. 2016, for Spain). However, such experimental conditions are hard to come by in a cross-country study based on cross-sectional data where the use of selectivity correction procedures based on exclusion restrictions are not easy to defend. Our approach relies instead on comparing workers with similar observable characteristics, except type of contract (our treatment). Hence, we need a large set of predetermined controls that should include proxies for ability and effort not usually available in observational data. Fortunately, the PIAAC survey does contain such proxies. Our preferred specification includes, in addition to workers' demographic characteristics — such as gender, age, and education — and occupation, industry, and firm size dummies, a set of covariates that proxy both workers' motivations and skills used at the workplace. 
To proxy the degree of worker's motivation, we define a dummy variable, motivation, that takes the value 1 when the individual claims to feel identified "to a great extent" or "to a very great extent" with learning new skills, working out difficult tasks, relating new things to what they already know, and seeking more information when they do not understand something. To further help mitigate reverse causality concerns, we also control for the worker's use of literacy and numeracy skills at the workplace. For this purpose, we define two additional dummy variables: reading skills takes value 1 if the job involves the daily use of reading skills, and 0 otherwise; and maths skills equals 1 when the job involves the daily use of mathematical skills, and 0 otherwise. Furthermore, in some specifications, we also use a dummy variable that reflects whether the worker uses any of the two types of skills at the workplace daily, skills.

It is plausible that differences in the training processes within the firm generate differences in workers' promotion opportunities to reach better contracts. However, the extent to which these differences in specific human capital accumulation could lead to differences in general human capital remains an open question. To address this issue, we analyze the effect of OJT activities on the two measurements of general cognitive skills reported in the PIAAC sample, namely, the test scores achieved on literacy and numeracy. Notice that by including a large range of controls (including educational attainments and parental background) in these last regressions, our interpretation of the latter results would be akin to "value-added" effects, namely the extra skills acquired through OJT on top of those predicted by above-mentioned individual characteristics.

In the sequel, we first present results for Spain that confirm that temporary contracts both reduce the probability and intensity of training and are also associated with lower levels of general skills. Next, we provide evidence on the effects of EPL gaps onto OJT gaps and general human capital using cross sectional variation across 13 European countries.

\section{Evidence on Spain}

\subsection{Sample characteristics and model specification}

Table 1 presents sample descriptive statistics in Spain of the main outcome variables in the subsequent empirical analysis, i.e., the availability and intensity of OTJ activities, the perception on the efficacy of the training process and, finally, the scores in both tests. At first sight, the evidence reported in Table 1 seem fairly consistent with the basic predictions of the model. Temporary workers undertake less training activities than permanent workers. This finding is robust both at the extensive margin (i.e., using $D^{O J T}$ as a measure of the availability of training) and the intensive margin (i.e., using $n^{O J T}$ as a measure of the intensity of training). Finally, both literacy and numeracy scores are significantly lower among temporary workers.

However, as stressed in Sect. 3, the negative relationship reported in Table 1 between temporary contracts and OJT activities does not necessarily imply causality, since both the type of contract and training activities could be jointly affected by other variables. To avoid such confounding issues in our analysis, it is essential to control for a vast array of potential factors which simultaneously affect the respective outcome variables 
Table 1 Descriptive statistics (Spanish PIAAC sample)

\begin{tabular}{|c|c|c|c|c|c|}
\hline Panel A & No. obs. & $\%$ Pop. $^{\mathrm{a}}$ & $\%$ Employed $^{\mathrm{a}}$ & \multicolumn{2}{|c|}{$\%$ Employees $^{\mathrm{a}}$} \\
\hline PIAAC sample & 6055 & & & & \\
\hline $16 \leq$ Age $<66$ & 5970 & & & & \\
\hline Workers & 3386 & 58.386 & & & \\
\hline Self-employed & 547.000 & 9.391 & 16.085 & & \\
\hline Employee & 2839 & 48.995 & 83.915 & & \\
\hline Temporary & 589 & 9.690 & 16.597 & \multicolumn{2}{|c|}{19.778} \\
\hline Panel B & Permanent $^{\mathrm{a}}$ & Temporary $^{\mathrm{a}}$ & Difference & $\mathrm{SD}$ & $p$ value \\
\hline Proportion with training & 48.323 & 31.577 & 16.746 & 0.023 & 0.000 \\
\hline$n^{O J T}$ & 1.376 & 0.737 & 0.639 & 0.123 & 0.000 \\
\hline Literacy test scores & 263.234 & 255.071 & 8.163 & 2.438 & 0.001 \\
\hline Numeracy test scores & 260.843 & 247.963 & 12.881 & 2.257 & 0.000 \\
\hline Panel C & $D^{O J T}=1^{\mathrm{a}}$ & $D^{O J T}=0^{\mathrm{a}}$ & Difference & $\mathrm{SD}$ & $p$ value \\
\hline Literacy test scores & 269.444 & 254.090 & 15.354 & 2.160 & 0.000 \\
\hline Numeracy test scores & 267.843 & 248.024 & 19.820 & 2.305 & 0.000 \\
\hline
\end{tabular}

Note: a worker has a temporary contract when he/she has a fixed-term contract, a temporary job with a temporary work agency or any type of training contract. The indicator $D^{O J T}$ takes the value 1 when the worker claims to have attended training activities in the last 12 months, and 0 otherwise. The variable $n^{O J T}$ measures the number of training activities attended by the worker during the past 12 months. The literacy and numeracy test scores statistics are obtained from the plausible values attributed from the responses to exercises which are part of the survey. The literacy test measures the ability to understand and use texts (written or in a digital format) in different contexts, while the numeracy test measures the use, application, interpretation and communication of mathematical information and ideas

a Population share using weights of the whole sample

(i.e., predetermined variables both related to training activities as well as the skills competence variables) and the treatment variable (type of contract).

To do so, we start by presenting in the next section the estimates obtained from several econometric models which include several types of controls. First, we use individuals' basic characteristics such as age, gender, educational attainment, marital status, children, immigrant status, and parental educational background. In addition, we also control for the degree of worker's motivation, motivation, and whether the worker uses reading or mathematical skills at the workplace daily, skills. In our preferred specification, we also include occupational, industry, and firm size dummies.

\subsection{EPL and OJT gaps}

Table 2 reports estimates and $p$-values of the marginal effect of temporary in a probit model explaining the probability of receiving training at the workplace $\left(D^{O J T}=1\right) .{ }^{7}$

\footnotetext{
${ }^{7}$ Detailed results of all models estimated in the paper are available upon request.
} 


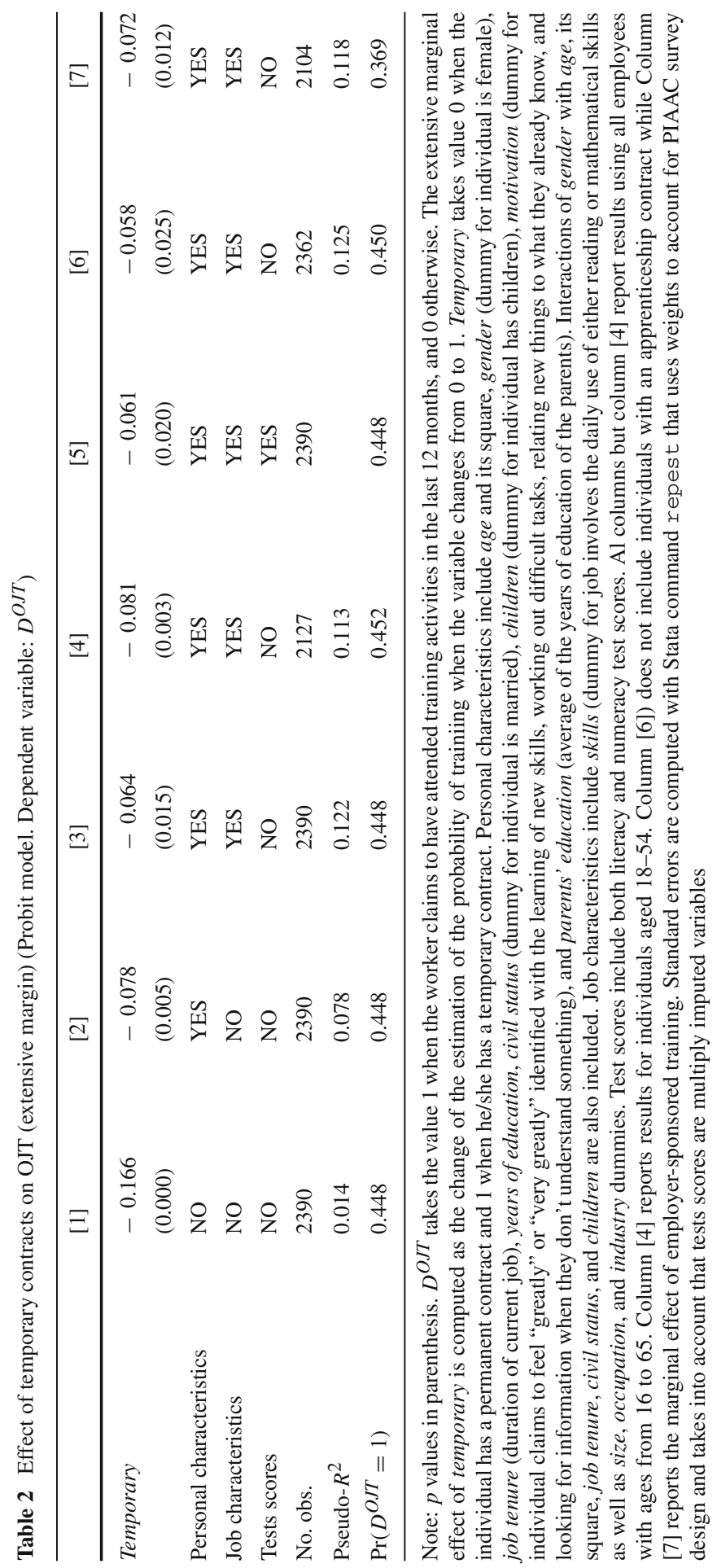


In column [1], we present the results in the case when type of contract is the only covariate in this model. In column [2], personal characteristics are added as covariates. These include (in addition to motivation), age of the respondent, age, (and its square), gender, female, the duration of current job, the years of completed education, a dummy for individual is married, married, a dummy for individual has children, parent, the average of the years of education of the parents. Interactions of female with age, its square, job tenure, married, and parent are also included. Finally, job characteristicsskills as well as firm size, occupation, and industry dummies - are added in column [3].

The main finding in the first three columns in Table 2 is that, in line with our main prediction, the estimate for the marginal effect of temporary is negative and statistically significant. Furthermore, the estimates suggest that the magnitude of the marginal effect is quantitatively very relevant. In the absence of further controls, the results in column [1] show that holding a temporary contract is associated with a reduction in the probability of receiving OJT of 16.6 percentage points, where the baseline probability of receiving OTJ among permanent workers is $44.8 \%$. By progressively adding further covariates the absolute size of the estimate decreases but remains highly significant. In our preferred variable specification, column [3], the estimated marginal effect is halved, falling to about -6.5 percentage points. As expected, when we restrict the sample to young and adult employees, the marginal effect is larger: Column [4] reports a negative marginal effect of over 8 percentage points for individuals aged 18 to 54 .

We further implement three robustness checks. First, we use column [5] as an informal way to check that the results reported in columns [1]-[4] are fairly robust to adding proxies for unobserved cognitive abilities. We do so by including the tests scores as additional covariates. These scores are measured at the time of the PIAAC survey and, therefore, they are endogenous. Nevertheless, we include them to exploit the fact that, under the plausible assumption that they are highly persistent in time, they approximate innate abilities. Hence, if unobserved cognitive abilities were strongly related to temporary, inclusion of the scores would change the estimated marginal effect. What we find is that the estimate is almost identical to the one obtained when the test scores are excluded. This suggests that the omission of controls for timeinvariant cognitive abilities is not likely to induce a large bias in our estimates.

Second, so far we have considered as temporary contracts all fixed-term contracts, including training and apprenticeship contracts. If all temporary contracts were training and apprenticeship contracts, the probability of training for a temporary worker would be equal to one. Thus, the inclusion of these two types of contracts in our sample may bias downwards the negative effect of holding temporary contracts on the probability of training. In column [6] we present estimates using the restricted sample of temporary contracts. Given that the number of training and apprenticeship contracts is very small (28 observations), the difference with the previous estimate is almost negligible.

Finally, the negative relation between temporary contracts and OJT follows directly under the assumption that the cost of training is fully covered by the firm (see the "Appendix"). To explore how sensitive is the probability of OJT to whether the worker covers the cost of training, in column [7] we restrict the sample to workers who had no training and workers whose training was fully employer-sponsored. The negative 
marginal effect, -7.2 percentage points which, despite being larger in magnitude, is not significantly different from the point estimate using our preferred specification.

Therefore, from this evidence one can infer that the detrimental effect of contractual instability on the specific training received in the workplace is substantial. For example, the estimate of the marginal effect reported in our preferred specification, column [3], implies that for the typical worker under a permanent contract, switching to a temporary contract reduces the probability of receiving training at the workplace by $14 \%(=0.064 / 0.448)$. For younger workers aged 18 to 54 the probability decreases even more, i.e. by around $18 \%(=0.08 / 0.448)$.

We next report in Table 3 the results on the effect of holding a temporary contract on the OJT intensive margin, namely, the number of training activities which the worker has attended over the past 12 months, $n^{O J T}$. In this case, we use a count data model based on the Negative Binomial distribution (which is used after rejecting the equality of mean and variance implied by the more restrictive Poisson distribution), in order to take account of the discrete nature of the new dependent variable.

The results are similar to those in Table 2 in the sense that the coefficient on temporary systematically exhibits a negative sign, indicating that holding a temporary contract reduces the expected number of OJT activities. However, unlike what happened in the probit model for $D^{O J T}$, the estimated coefficient on this variable is only statistically significant at around the $10 \%$ percent level when all the controls are included in the sample of workers aged 16-65, column [2]. As in the extensive mar-

Table 3 Effect of temporary contracts on OJT (intensive margin)(Negative binomial model (coefficients). Dependent variable: $n^{O J T}$ )

\begin{tabular}{lllllll}
\hline & {$[1]$} & {$[2]$} & {$[3]$} & {$[4]$} & {$[5]$} & {$[6]$} \\
\hline Temporary & -0.623 & -0.222 & -0.318 & -0.310 & -0.313 & -0.322 \\
& $(0.000)$ & $(0.117)$ & $(0.020)$ & $(0.022)$ & $(0.022)$ & $(0.087)$ \\
Personal characteristics & NO & YES & YES & YES & YES & YES \\
Job characteristics & NO & YES & YES & YES & YES & YES \\
Tests scores & NO & NO & NO & YES & NO & NO \\
Alpha & 2.312 & 1.674 & 1.604 & 1.599 & 1.589 & 1.938 \\
& $(0.000)$ & $(0.000)$ & $(0.000)$ & $(0.000)$ & $(0.000)$ & $(0.000)$ \\
No. obs. & 2388 & 2388 & 2126 & 2126 & 2100 & 1865 \\
Pseudo- $R^{2}$ & 0.006 & 0.054 & 0.059 & 0.059 & 0.059 & 0.057 \\
\hline
\end{tabular}

Note: $p$ values in parenthesis. Dependent variable $n^{O J T}$ measures the number of training activities in the past 12 months. The intensive marginal effect of temporary measures the expected increase in number of activities when the variable changes from 0 to 1 . Temporary takes value 0 when the individual has a permanent contract and 1 when he/she has a temporary contract. Parameter $\alpha$ is assumed to be positive and its estimate reflects the level of overdispersion in the count data. See Note in Table 2 for the definition of personal and job characteristics. Test scores include both literacy and numeracy test scores. Columns [1] and [2] report results for workers aged 16-65. Columns [3]-[6] report results for younger workers aged 18-54. Column (5) does not include individuals with an apprenticeship contract while Column (6) reports the effect of employer-sponsored training activities. Standard errors are computed with Stata command repest that uses weights to account for PIAAC survey design and takes into account that tests scores are multiply imputed variables 
gin, results are stronger and more significant for the sample of workers aged 18-54. Column [3] reports the results for workers within this age bracket using all covariates. Excluding training contracts, column [5], or using only employer-sponsored training, column [6], hardly changes the magnitude and the statistical significance of the estimates.

A brief summary of the main findings reported so far indicates that holding a temporary contract exhibits a negative relationship with training availability and intensity, especially for young and adult workers.

\subsection{OJT and test score gaps}

In view of these results, the next step is to check how the availability or the intensity of OJT activities is related to the individual's cognitive skills (human capital), measured by the test in the PIAAC literacy and numeracy tests. To do so, we first present the results derived from estimating regression models using these scores as dependent variables. In both models the covariate of interest is the extensive margin of OJT, $D^{O J T}$. The dummy variable temporary is excluded from the set of controls in order to test whether the effect of this variable on the test scores is mainly due to the amount of OJT workers receive at the workplace, and not to any other channels related to holding such contracts.

Table 4 presents the estimated coefficients in such regressions where the dependent variable is literacy and numeracy scores, respectively. Covariates are those used in the previous models with the exception of skills, which is replaced by reading skills and maths skills, respectively. Columns [1] and [2] report results for literacy results while columns [3]-[6] report results for numeracy results. Our results show that the raw difference in literacy scores between permanent and temporary workers, column [1], disappears once we control for all available covariates. By contrast, as shown in columns [4] to [5], this is not the case for numeracy, where training leads to an increase of about 3 percentage points in these scores, even after controlling for the use of math skills, column [4]. To explore the relation between the number of training activities and the numeracy scores, in column [5] we add the number of activities minus one, $n^{O J T]}-1$, as a covariate to the regression in column [4]. The estimate of the parameter associated to this variable reflects the effect that an additional training activity has on math skills. The point estimate is positive, but small in magnitude and not precisely estimated. As a result, we do not find evidence of an additional effect in the number of training activities.

Therefore, our evidence suggests that the availability of training at the workplace is associated with a significant improvement of workers' maths skills. In order to check whether this correlation is mainly due to holding a temporary contract, in column [6] we add temporary and its interaction with $D^{O J T}$ as additional covariates. The coefficients are not significant. Thus, we conclude that OJT plays an important role in explaining the relationship between type of contracts and PIAAC math scores.

Finally, Table 5 reports the estimated coefficients obtained from the reduced forms of, respectively, the literacy and numeracy test scores, in which the training variables $D^{O J T}$ and $n^{O J T}$ are replaced by the temporary dummy variable. The idea of these 
Table 4 Effect of on-the-job training on test scores (Weighted least squares)

\begin{tabular}{|c|c|c|c|c|c|c|}
\hline & \multicolumn{2}{|l|}{ Literacy } & \multicolumn{4}{|c|}{ Numeracy scores } \\
\hline & [1] & [2] & [3] & [4] & [5] & [6] \\
\hline \multirow[t]{2}{*}{$D^{O J T}$} & 14.623 & 0.289 & 18.310 & 3.498 & 3.428 & 3.890 \\
\hline & $(0.000)$ & $(0.871)$ & $(0.000)$ & $(0.088)$ & $(0.129)$ & $(0.119)$ \\
\hline \multirow[t]{2}{*}{$n^{O J T}-1$} & & & & & 0.050 & \\
\hline & & & & & $(0.850)$ & \\
\hline \multirow[t]{2}{*}{ Temporary } & & & & & & -1.324 \\
\hline & & & & & & $(0.666)$ \\
\hline \multirow[t]{2}{*}{ Temporary $\times D^{O J T}$} & & & & & & -3.600 \\
\hline & & & & & & $(0.413)$ \\
\hline Personal characteristics & NO & YES & NO & YES & YES & YES \\
\hline Job characteristics & NO & YES & NO & YES & YES & YES \\
\hline No. obs. & 2344 & 2344 & 2343 & 2343 & 2342 & 2125 \\
\hline$R^{2}$ & 0.027 & 0.319 & 0.040 & 0.332 & 0.333 & 0.327 \\
\hline
\end{tabular}

Note: $p$ values in parenthesis. All employees with ages from 18 to 54. Dependent variables are PIAAC plausible values for literacy and numerical test scores. Columns [1] and [2] reports results for literacy test scores. Columns [3]-[6] report results for numeracy test scores. $D^{O J T}$ takes the value 1 when the worker claims to have attended training activities in the last 12 months, and 0 in the opposite case. $n^{O J T}$ measures the number of training activities in the past 12 months. Control temporary takes value 0 when the individual has a permanent contract and 1 when he/she has a temporary contract. See Note in Table 2 for the definition of personal characteristics. Job characteristics include size, occupation, and industry dummies. In the literacy scores model, it also includes reading skills, which is an indicator that the job involves the daily use of reading skills. In the numeracy scores model, it also includes maths skills, which is an indicator that the job involves the daily use of maths skills. Standard errors are computed with Stata command repest that uses weights to account for PIAAC survey design and takes into account that tests scores are multiply imputed variables

reduced forms is that, if the mechanism we explore is valid, we should expect that, ceteris paribus, being a temporary worker has a negative effect on the scores mainly through the reduction of the amount of OJT they undertake, and not so much through other alternative channels. The estimates of the coefficients on temporary are negative in all specifications once we control for all covariates. Unfortunately, when we run the regression for numeracy scores we do not find a significant coefficient (column [4], $p$ value of $20.2 \%$ ), although the point estimate is similar in magnitude to the direct effect of OJT. Given that most of the parameters in the regression are actually not statistically significant, one plausible explanation for the lack of significance of the estimate for temporary is that the link we try to capture in the reduced form is, given the sample, too weak to be precisely estimated. To explore this possibility, in column [5] we simplify the specification by dropping all covariates in our sample for which the $p$ value of the significance level exceeds $20 \%$. In this restricted specification, the point estimate of temporary increases from -3.713 to -4.649 and becomes almost statistically significant at the $5 \%$ level. Hence, we interpret this last finding as somewhat supportive to the detrimental role that temporary contracts play in the accumulation of skills, as least in regards to numerical ones. 
Table 5 Reduced-form effect of temporary contract on test scores (Weighted least squares)

\begin{tabular}{|c|c|c|c|c|c|}
\hline & \multicolumn{2}{|l|}{ Literacy } & \multicolumn{3}{|c|}{ Numeracy scores } \\
\hline & {$[1]$} & {$[2]$} & {$[3]$} & {$[4]$} & {$[5]$} \\
\hline \multirow[t]{2}{*}{ Temporary } & -9.225 & -0.632 & -13.561 & -3.713 & -4.649 \\
\hline & $(0.000)$ & $(0.816)$ & $(0.000)$ & $(0.202)$ & $(0.069)$ \\
\hline Personal characteristics & NO & YES & NO & YES & $\mathrm{YES}^{\mathrm{a}}$ \\
\hline Job characteristics & $\mathrm{NO}$ & YES & $\mathrm{NO}$ & YES & $\mathrm{YES}^{\mathrm{a}}$ \\
\hline No. obs. & 2126 & 2126 & 2125 & 2125 & 2125 \\
\hline$R^{2}$ & 0.008 & 0.316 & 0.016 & 0.325 & 0.299 \\
\hline
\end{tabular}

Note: $p$ values in parenthesis. All employees with ages from 18 to 54 . Dependent variables are PIAAC plausible values for literacy and numerical test scores. Columns [1] and [2] reports results for literacy test scores. Columns [3]-[5] report results for numeracy test scores. Control temporary takes value 0 when the individual has a permanent contract and 1 when he/she has a temporary contract. Reading skills and maths skills are dummies for job involves the daily use of either reading or mathematical skills, respectively. See Note in Table 2 for the definition of personal and job characteristics. Column [5] reports results after dropping non-significant (at 20\% significance level) controls in column [4]. Standard errors are computed with Stata command repest that uses weights to account for PIAAC survey design and takes into account that tests scores are multiply imputed variables

a The set of controls include age and its square, years of education, the interaction between civil status and a dummy for female, four major occupational dummies, one industry dummy, and maths skills

\section{European cross-country evidence}

In this section, we provide further evidence on the general validity of the mechanism discussed above for other European countries besides Spain. In particular, we analyze if the OJT gap between permanent and temporary workers is larger in labor markets with highly discontinuous severance pay schemes. In particular, we consider a pooled data of around 40,000 observations for 13 countries (including Spain), out of those that participated in PIAAC. We focus exclusively on European countries because we wish to minimize camparability problems in the measures of EPL gaps. The choice of specific countries is dictated by the availability in their datasets of the same covariates that were used before for the analysis of our case study of Spain. ${ }^{8}$

\subsection{EPL gaps}

Our empirical strategy here adapts the one used for Spain to this cross-country study. For example, we run Probit and Negative Binomial regressions of extensive and intensive margins of OJT on the temporary contract dummy, a proxy of the EPL gap and the interaction between these two variables, in addition to the remaining covariates mentioned earlier. This would allow for a direct assessment of the link between EPL gaps and the impact of temporary work on our measures of OJT across countries. Notice that the interpretation of the interaction effect would even remain meaningful

\footnotetext{
8 Our sample of European countries includes Belgium, Czech Republic, Denmark, France, Ireland, Italy, Netherlands, Norway, Poland, Slovak Republic, Spain, Sweden, and United Kingdom.
} 
in presence of confounding unobserved factors that could bias the country-specific effects insofar the bias is not related to the EPL gaps (i.e., under the assumption that the bias is the same in all countries). In addition the statistical significance of the interaction term would allow for a direct assessment of the relevance between EPL gaps and the effects of holding a temporary contract on OJT.

To construct a country-level proxy of dual EPL, we use information drawn from OECD (2013, item 7: "Compensation following unfair dismissal") for permanent contracts and OECD (2014, Table 4.4, Column 4: "Severance pay at end date") for temporary contracts. Using both pieces of information, we compute the gap in 2012 between the mandated severance pay (in terms of monthly wages) of an unfair dismissal of a permanent worker with four years of tenure and the total compensation pay (also in terms of monthly wages) associated to hiring four temporary workers in sequence with a one-year contract each which is not renewed at its end date. ${ }^{9}$ The choice of four years relies on the existence of limits in some countries to use temporary contracts beyond that duration. ${ }^{10}$ Whenever costs of dismissals are the same for both contracts, the corresponding EPL gap is set equal to zero.

The construction of the EPL gap for each country in our sample is based on the following two pieces of information. On the one hand, OECD (2013) provides a detailed account of EPL rules for permanent contracts in OECD countries during 20122013. There are 21 items for each country summarizing severance pay, notice periods, rules for fair/unfair and for personal/collective dismissals, etc.; these items become inputs in the design of the well-known EPL categorical indicators which have been widely used in the literature (see, e.g., Boeri et al. 2017, for an overview). In particular, we choose item 7 where OECD provides a representative/average calculation in terms of monthly wages of "compensation following unfair dismissal of a worker under a permanent contracts with 20 years of tenure". Following our benchmark comparison of the redundancy costs for a firm which lays off a worker with a permanent contract after 4 years of tenure against hiring four workers in sequence under one-year long temporary contracts, the corresponding figure in item 7 is divided by 5. Column [2] in Table 6 gathers the severance pay for permanent contracts in each country. On the other hand, regarding EPL for temporary contracts, we use information from OECD (2014, Table 4.4), which provides detailed descriptions of difficulty of dismissals, severance and notice period, procedural inconveniences, etc. Specifically we choose the item "notice and severance at end date of contract", expressed in monthly wages per year of service and multiplied it by 4 . In some cases there is no compensation or it is the same as for temporary contracts. Column [3] in Table 6 gathers this temporary contracts non-renewal compensation cost. Finally, column [4] reports the EPL gap. As

\footnotetext{
9 For example, in 2012, the dismissal costs of an unfair dismissal of a permanent worker in our illustrative country (Spain) were 33 days (of wages per year of service), so that after 4 years the total amount received by the worker would be $132=4 \times 33$ days. Each temporary worker was entitled to a compensation of 10 days for the nonrenewal of her contract, so that the cost of the alternative strategy of hiring four temporary workers in sequence amounts to $40=4 \times 10$ days). Thus the EPL gap is $92=132-40$ days, or about 3.1 monthly wages.

10 Yet, the gap would be proportional for any other job tenure of the dismissed worker (usually up to a cap between 20 and 30 years of tenure). So, for example, if the aforementioned hiring strategy were to last for 8 years, instead of 4 years, the gap would double.
} 


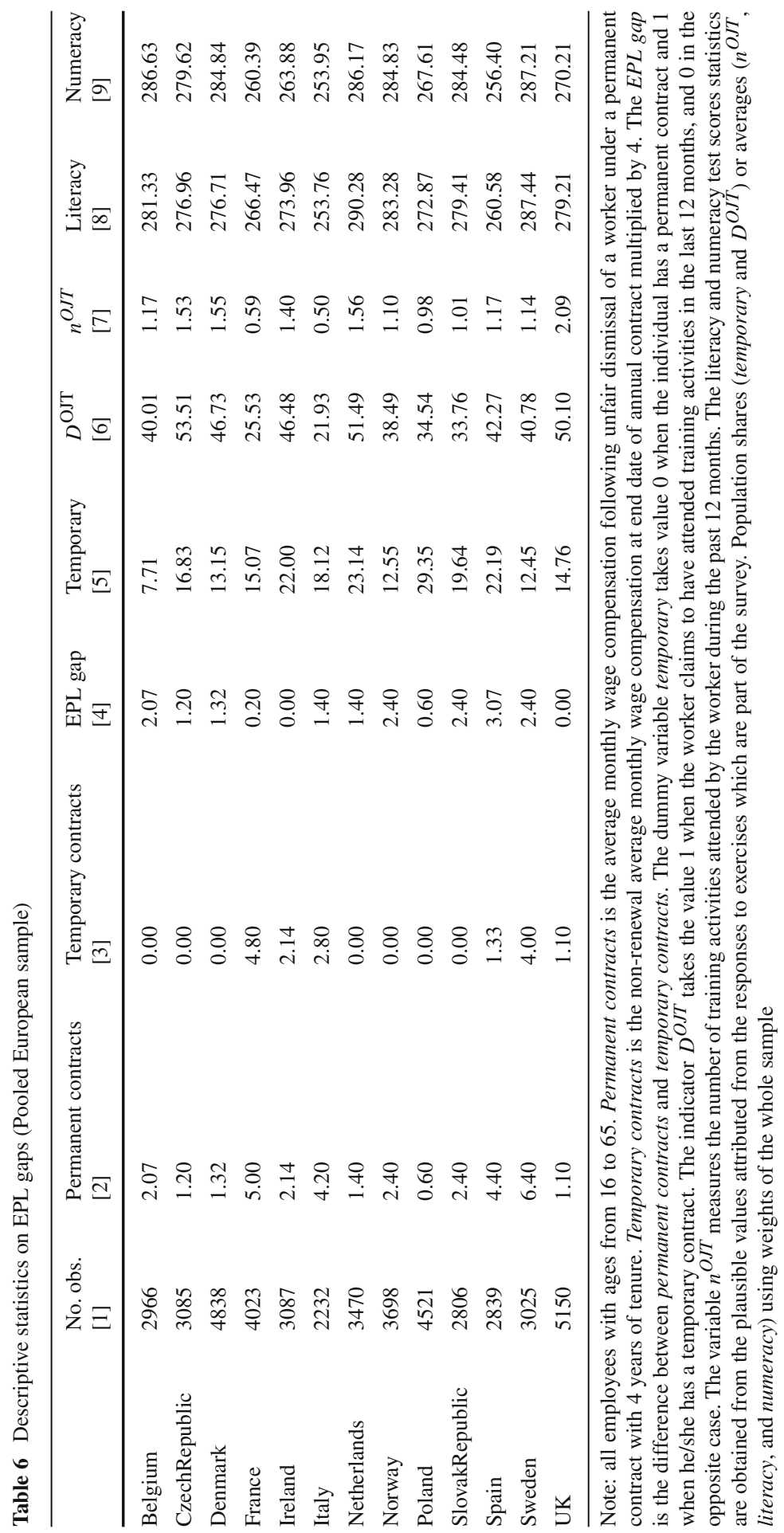


can be seen, gaps range from about three monthly wages in Spain to zero in Ireland and the UK. If we were interested in the EPL gap at tenure $d \neq 4$ then the figures reported in column [3] should be multiplied by $d / 4$. Finally, columns [5]-[9] presents country-specific weighted averages of the variables of interest in this study (share of temporary contracts, training and test scores).

\subsection{Pooled regressions}

The first two columns in Table 7 show the estimated marginal effects/coefficients for temporary and its interaction with EPL in the Probit and Negative Binomial models for OJT availability $\left(D^{O J T}\right)$ and OJT intensity $\left(n^{O J T}\right)$ for our pooled datasets. Likewise, for completeness, the last two columns report the coefficients on the two margins of training, and their interactions with the EPL gaps, in regressions with the literacy and numeracy test scores as dependent variables. In all instances, the estimated models include country dummies while the remaining set of covariates is the one used in the most extensive specifications presented in Tables 2, 3, 4, 5 and 6 for Spain. Notice that the inclusion of country dummies prevents introducing the EPL gap on its own as an additional covariate since this would lead to perfect multicollinearity between both sets of regressors.

As can be inspected in the first two columns, the estimated coefficients on the interaction terms are negative. The estimates are significant in the extensive margin, indicating that training gaps increase in countries where EPL gaps are large. For example, consider the UK, one of the countries with unified employment protection $($ EPL gap $=0$ ) and where the unconditional probability of OJT is $50.1 \%$ (see Table 6). According to the results, the gap in the extensive margin of OJT for the UK is 8.0 percentage points. In Spain, the epitome of a dual labor market (EPL gap $=3.1$ ) and where the unconditional probability of OJT is much lower, 42.27\%, the gap in extensive OJT jumps to 26 percentage points $(=0.080+0.058 \times 3.1)$. As regards the link between test score gaps and OJT gaps, the last two columns show how differentials in the extensive margin of OJT are correlated with gaps in both literacy and numeracy skills. We find no evidence that EPL gaps play any role in this channel. The effects of the OJT intensive and extensive margins on both test scores are positive, whereas the estimated coefficients on the interaction terms are not always negative and are often statistically insignificant.

\subsection{Country-specific regressions}

The results from the pooled regressions exploit both within country and between country variations. To analyze how the estimates depend on between country differences in EPL gaps, in this section we present a brief summary of results from within country estimations of the models estimated so far for the OJT extensive and intensive margins. ${ }^{11}$ Figure 2 plots the coefficient estimates for temporary in the within-country

11 For brevity, we do not report the results on the effect of OJT on test scores since, as discussed previously, the evidence is mixed. However, they are available on request. 
Table 7 Effect of Dual EPL on OJT and PIAAC test scores (Pooled sample. Weighted least squares)

\begin{tabular}{lllll}
\hline Dep. var./covariates & $D^{\text {OJT }}$ & $n^{\text {OJT }}$ & Literacy & Numeracy \\
\hline Temporary & -0.080 & -0.099 & & \\
Temporary $\times$ gap & $(0.078)$ & $(0.237)$ & & \\
$D^{\text {OJT }}$ & -0.058 & -0.089 & & \\
& $(0.023)$ & $(0.134)$ & & 4.240 \\
$D^{\text {OJT }} \times$ gap & & & 5.118 & $(0.013)$ \\
& & & $(0.001)$ & 0.288 \\
$n^{\text {OJT }}-1$ & & -0.961 & $(0.751)$ \\
& & & $(0.205)$ & 0.187 \\
$\left(n^{O J T}-1\right) \times$ gap & & & 0.075 & $(0.385)$ \\
& & & $(0.657)$ & -0.195 \\
Personal characteristics & YES & YES & -0.067 & $(0.052)$ \\
Job characteristics & YES & YES & YES & YES \\
No. obs. & 39215 & 39172 & 42342 & YES \\
Pseudo- $R^{2}, R^{2}$ & 0.115 & 0.056 & 0.311 & 35431 \\
\hline
\end{tabular}

Note: $p$ values in parenthesis. All employees with ages from 18 to 54 . $D^{O J T}$ takes the value 1 when the worker claims to have attended training activities in the last 12 months, and 0 in the opposite case. $n^{O J T}$ measures the number of training activities in the past 12 months. literacy and numeracy are PIAAC plausible values for literacy and numerical test scores, respectively. Control temporary takes value 0 when the individual has a permanent contract and 1 when he/she has a temporary contract while gap is the countrylevel difference between the average monthly wage compensation following unfair dismissal of a worker under a permanent contract with 4 years of tenure and four times the non-renewal average monthly wage compensation at end date of annual contract. All specifications include country dummies as well as personal and job characteristics. Personal characteristics include age and its square, gender (dummy for individual is female), job tenure (duration of current job), years of education, civil status (dummy for individual is married), children (dummy for individual has children), motivation (dummy for individual claims to feel "greatly" or "very greatly" identified with the learning of new skills, working out difficult tasks, relating new things to what they already know, and looking for information when they don't understand something), and parents' education (average of the years of education of the parents). Interactions of gender with age, its square, job tenure, civil status, and children are also included. Job characteristics include size, occupation, and industry dummies. They also include skills (dummy for job involves the daily use of either reading or mathematical skills) in the first two columns and reading skills and maths skills (dummies for job involves the daily use of either reading or mathematical skills) in the third and fourth column, respectively. Standard errors are computed with Stata command repest that uses weights to account for PIAAC survey design and takes into account that tests scores are multiply imputed variables

probit models for the extensive OJT margin, $D^{O J T}$, against our country-specific EPLgaps. The model specification includes all personal and job characteristics as in column [3] from Table 2.

The main finding is that, with the exception of Ireland and the Netherlands, the relationship between holding a temporary contract and the extensive margin of OJT is negative and significant at the $10 \%$ percent level. Figure 2 also shows that the negative relation between EPL gaps and how temporary status affects OJT reported 


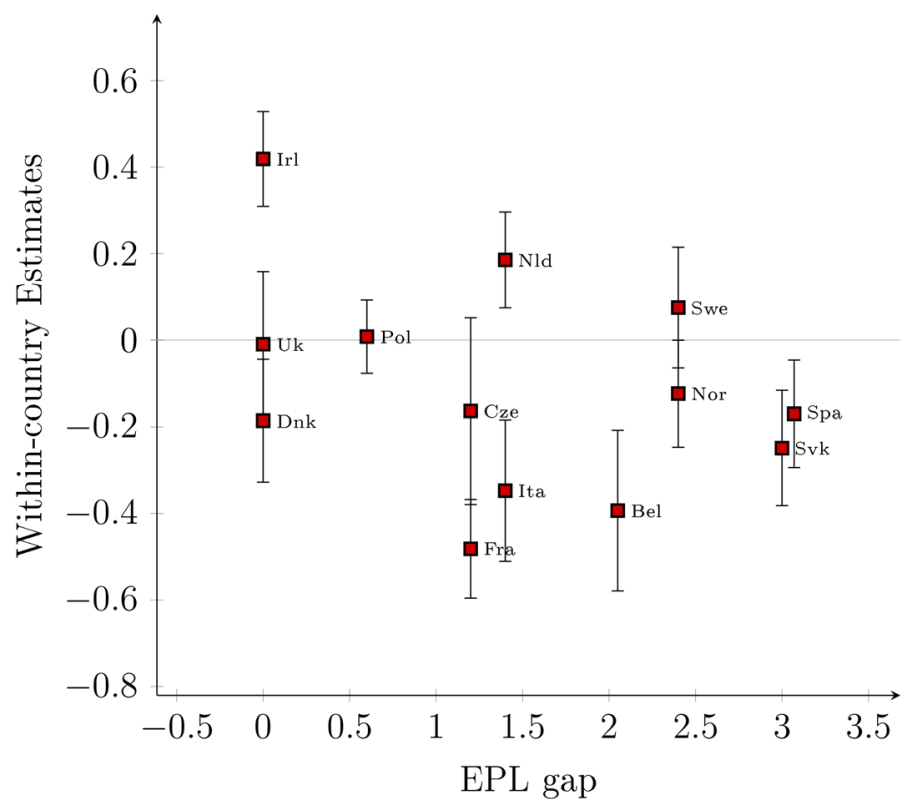

Fig. 2 Within-country $D^{O J T}$ probit model with all covariates. Note: Coefficient estimates for temporary with $90 \%$ confidence intervals versus country-specific EPL gaps from Table 6 are displayed in this figure

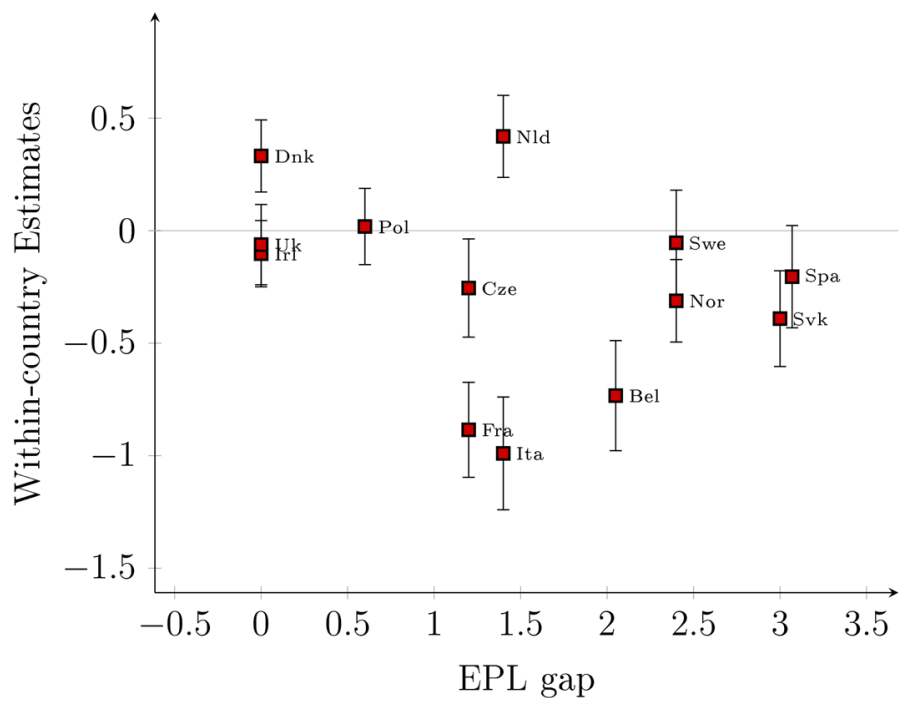

Fig. 3 Within-country $n^{O J T}$ negative binomial model with all covariates. Note: Coefficient estimates for temporary with $90 \%$ confidence intervals versus country-specific EPL gaps from Table 6 are displayed in this figure

in Table 7 is not driven by any subgroup of countries. The same conclusions can be reached when looking at the results for intensive margin OJT activities, $n^{O J T}$, plotted in Fig. 3. 


\section{Conclusions}

We began this paper by arguing that the gap in OJT between permanent and temporary workers tends to be larger in labor markets where the transition to job stability is low, because of their dual EPL structure. On the basis of this observation, our goal here has been to analyze how the gap in severance pay between these types of workers may have affected the extensive and intensive margins of OJT that they receive at the workplace. The theoretical motivation of our empirical analysis is as follows. In a context where firms and workers sort into permanent and temporary contracts, and where wages are not fully flexible, a high EPL gap leads to a high turnover of temporary workers (low temp-to-perm conversion rates), while permanent workers enjoy much greater job stability, given their much more stringent employment protection. Hence, as a result of these differences in expected job durations, firms find much more profitable to invest on permanent workers than on temporary workers. In addition, we argue that the underinvestment in training that temporary workers experience may have negative consequences over the skills competences that they acquire beyond the education system.

The cross-sectional database provided by PIAAC is used to explore these issues. Specifically, the availability of several different OJT measures, as well as workers' test scores on literacy and numeracy, allows us to check, firstly, the direct relation between the type of contract held by workers and the amount of OJT they receive and, secondly, whether the gap in training is correlated with the gap in cognitive skills.

We present econometric results for several outcome variables: two measures of training activities (availability and intensity), and another two measures of cognitive skills. For each econometric model, we report results using different specifications. In our broader specification we consider (in addition to the temporary contract indicator) a wide set of person-level demographics, including proxy variables of the workers' family background, ability, motivation, skills used at the workplace, and job characteristics.

Using Spanish PIAAC data as an illustrative case study of the mechanism at hand, our main empirical findings support in general the existence of a positive relationship between labor market dualism and the training gap at the workplace, as well as a positive relationship between the amount/intensity of OJT activities and workers' cognitive skills. How should we interpret these results? In principle it is not evident OJT investments are a detrimental or a favorable outcome of dual labor markets. In effect, if training for permanent workers is sufficiently large, then workers in a country with high firing costs and a dual labor-market structure may have greater overall OJT investment than in another economy with a more unified labor market structure. This is likely to depend on other factors as well. Among them, there are the efficiency of the education system, the industrial specialization of the economy (high value vs. low value-added industries), and the probability that temporary workers obtain permanent contracts at some point in their careers.

The Spanish economy fares rather unsatisfactorily in these three outcomes. Its educational system does not perform well in international comparisons (see Ciccone and Fontes 2008), the economy has been heavily dependent on the real estate and touristic sectors (see Garriga 2010) and, as already mentioned, the temp-to-perm conversion rate is very low. By the same token, given their large turnover, temporary workers may lack the right incentives to improve on their job performance by acquiring better pro- 
ductive capabilities. Hence, since these skills and OJT are important components of multifactor productivity, this mechanism may have played a relevant role in explaining the unsatisfactory development of TFP growth in Spain and other EU countries with highly segmented labor markets (see Bassanini et al. 2009; Dolado et al. 2016).

Furthermore, our results seem to hold for a wider set of European countries which differ in their degree of labor market dualism. In general, we find that in those countries where the EPL gap is large, the gap in training and in cognitive skills is also large. This could explain why temporary contracts become dead ends in dual labor markets whereas they play the role of stepping stones towards more stable jobs in more unified labor markets.

Although admittedly the cross-sectional nature of PIAAC makes it difficult to derive neat causal statements from such results, we argue however that the evidence presented here suggests that the proposed mechanism may have played a relevant role in explaining the previous facts.

Open Access This article is distributed under the terms of the Creative Commons Attribution 4.0 International License (http://creativecommons.org/licenses/by/4.0/), which permits unrestricted use, distribution, and reproduction in any medium, provided you give appropriate credit to the original author(s) and the source, provide a link to the Creative Commons license, and indicate if changes were made.

\section{Appendix: A model of OJT in a dual labour market}

\section{A.1 Preliminaries}

In our stylized model, inspired by Berton and Garibaldi (2012)'s search and matching model of a dual labor market, there is mass one of risk-neutral workers who actively search for a job when unemployed. Workers differ in their (time-invariant) flow utility being unemployed, denoted by $z$ which is not observable to firms and is drawn from a continuous c.d.f. $G(z)$ over the support $[0, \bar{z}]$. Since this idiosyncratic utility of leisure is not observable, workers are identical for firms.

Labour productivity is $y>0$ and each job is subject to an adverse permanent shock whereby productivity falls to 0 with instantaneous probability $\mu$. Two types of labor contract exist in the economy: temporary and permanent contracts. In our setup, they differ in that dismissals of permanent workers entail severance pay $F>0$ (i.e., a transfer from the firm to the worker) whereas $F=0$ when dismissing temporary workers. Thus, $F$ can be interpreted as the redundancy pay gap between these types of workers. ${ }^{12}$ Furthermore, there is a probability $\alpha$ that a temporary contract may be transformed into a permanent one in the same job. ${ }^{13}$ Following Dolado et al. (2016), it is assumed that this conversion rate is decreasing in $F$, namely, $\alpha^{\prime}(F)<0$.

\footnotetext{
12 As explained earlier, our model departs from Berton and Garibaldi (2012) in that these authors assume that workers under permanent contracts cannot be dismissed when an adverse productivity shock occurs while temporary contracts can be terminated at will. In their model, firms hiring workers under permanent contracts can only rely on quits from existing jobs for downsizing, an assumption that we do not need in our version entailing severance pay.

13 Notice that $\alpha=\beta(1-\mu)$ where $\beta$ is the temp-to-perm conversion rate.
} 
Firms can freely decide on to open either temporary or permanent $(i=p, t)$ vacancies in different submarkets at an identical flow posting cost equal to $c$. Unemployed workers are freely to move across submarkets but cannot search simultaneously on both. Thus there is direct search. In each submarket, frictions are modeled through standard matching functions $m\left(u_{i}, v_{i}\right)$, where $u_{i}$ and $v_{i}$ denote the measures of vacancies and unemployed workers in submarket $i$, respectively. From each matching function we can define the corresponding job filling rate $q_{i}\left(\theta_{i}\right)$ and the job finding rate $h_{i}\left(\theta_{i}\right)=\theta_{i} q_{i}\left(\theta_{i}\right)$ in the $i$ th submarket, where $\theta_{i}=v_{i} / u_{i}$ is the submarketspecific labor market tightness. As is well known, $q_{i}\left(\theta_{i}\right)$ and $h_{i}\left(\theta_{i}\right)$ are decreasing and increasing functions of $\theta_{i}$, respectively and are assumed to satisfy the standard Mortensen-Pissarides conditions when $\theta_{i} \rightarrow 0$ and $\theta_{i} \rightarrow \infty$.

Each match signs a contract that sets a wage for the entire employment relationship without ex-post renegotiation. Berton and Garibaldi (2012) argue that this wage setting is in the spirit of Hall (2005) whereby any wage within the parties' bargaining set at the time of job creation can be supported as an equilibrium. To make the problem interesting we follow these authors in assuming that $w_{p}=w_{t}=w$, and $\bar{z}<w<y$, so that all workers participate in the labor market and, to capture no discriminatory rules for workers in different submarkets, wages are set to be the same. Finally the equilibrium of the model is characterized by free-entry conditions in each submarket and by workers' sorting across submarkets.

\section{A.2 Asset values}

Permanent contracts submarket Let $U_{p}(z)$ and $W_{p}(z)$ denote asset values for an unemployed worker and for an employed worker in submarket of permanent contracts. Likewise, let $J_{p}(z)$ and $V_{p}$ be the asset values of a permanent job and vacancy, respectively. The Bellman equations are:

$$
\begin{aligned}
r U_{p}(z) & =z+h_{p}\left(\theta_{p}\right)\left[W_{p}(z)-U_{p}(z)\right] \\
r W_{p}(z) & =w+\mu\left[U_{p}(z)+F-W_{p}(z)\right] \\
r J_{p}(z) & =y-w+\mu\left[V_{p}-F-J_{p}(z)\right] \\
r V_{p} & =-c+q_{p}\left(\theta_{p}\right)\left[J_{p}(z)-V_{p}\right]
\end{aligned}
$$

where (A.3) takes into account that a firm dismissing a permanent worker with probability $\mu$ has to pay severance pay equal to $F$. Assuming free entry in this submarket, $V_{p}=0$, and using (A.3) and (A.4) yields:

$$
\begin{aligned}
J_{p}(z) & =\frac{y-w-\mu F}{r+\mu}>0 \\
c & =q_{p}\left(\theta_{p}\right) J_{p}(z)
\end{aligned}
$$

Temporary contracts submarket With similar notation for the asset values in this submarket (this time using subscript $t$, we get the following Bellman equations:

$$
r U_{t}(z)=z+h_{t}\left(\theta_{t}\right)\left[W_{t}(z)-U_{t}(z)\right]
$$




$$
\begin{aligned}
r W_{t}(z) & =w+\mu\left[U_{t}(z)-W_{t}(z)\right]+\alpha(F)\left[W_{p}(z)-W_{t}(z)\right] \\
r J_{t}(z) & =y-w+\mu\left[V_{t}-J_{t}(z)\right]+\alpha(F)\left[J_{p}(z)-J_{t}(z)\right] \\
r V_{t} & =-c+q_{t}\left(\theta_{t}\right)\left[J_{t}(z)-V_{t}\right]
\end{aligned}
$$

From (A.5), (A.9) and (A.10), we get: $V_{i}$

$$
\begin{aligned}
J_{t} & =\frac{y-w+\alpha(F) J_{p}}{r+\mu+\alpha(F)}=\frac{y-w}{r+\mu+\alpha(F)}+\frac{\alpha(F) y-w-\mu F}{r+\mu} \\
c & =q_{t}\left(\theta_{t}\right) J_{t}(z)
\end{aligned}
$$

It can be easily checked that $(r+\mu+\alpha(F))\left[J_{t}(z)-J_{p}(z)\right]=\mu F>0$, and so $J_{t}(z)>J_{p}(z)$. The insight for this inequality is that, despite having lower expected duration, it is more profitable for firms to fill a temporary job since they do not need to pay firing costs in the face of adverse productivity shocks. Moreover, since $q_{t}\left(\theta_{t}\right) j_{t}(z)=q_{p}\left(\theta_{t}\right) J_{p}(z)$ from (A.6) and (A.12), it must be from the properties of the matching functions that $q_{t}\left(\theta_{t}\right)<q_{p}\left(\theta_{p}\right)$ and, conversely, $h_{t}\left(\theta_{t}\right)>h_{p}\left(\theta_{p}\right)$. The former inequality implies that the job filling rate of a permanent vacancy is larger than that of a temporary vacancy whereas the opposite holds for the job finding rates.

Workers sorting As Berton and Garibaldi (2012) point out, unemployed workers take as given the above-mentioned job finding rates and decide optimally in which submarket to search for a job by comparing $U_{p}(z)$ to $U_{t}(z)$. If $U_{t}(z)>U_{p}(z)$, they will search in the submarket of temporary contracts, and vice versa. This leads to the existence of a threshold value for the utility of leisure, $z^{*}$, such that $U_{t}\left(z^{*}\right)=U_{p}\left(z^{*}\right)$ implying that unemployed workers search in the submarket of permanent contracts for $z>z^{*}$. Combining (A.1) with (A.2) and (A.7) with (A.8) yields

$$
z^{*}=w-\frac{h_{p}\left(\theta_{p}\right)\left(r+\mu+h_{t}\left(\theta_{t}\right)\right)-\alpha(F)\left(h_{t}\left(\theta_{t}\right)-h_{p}\left(\theta_{p}\right)\right.}{(r+\mu)+\left(h_{t}\left(\theta_{t}\right)-h_{t}\left(\theta_{t}\right)\right)} \mu F
$$

so that, for a sufficiently small value of $\alpha$, the coefficient on $F$ is positive and thus an increase in $F$ lowers $z^{*}$. For $F=0, z^{*}=w>\bar{z}$. The intuition is simple: since the wage is the same across the two submarkets, in the absence of severance pay, the fact that the job finding rate is higher for temporary jobs implies that it is better for workers to search for a job in that submarket. By contrast, under severance pay, permanent jobs become more attractive.

Decisions on training Following Berton and Garibaldi (2012) again, we consider the possibility that firms may be able to return to high productivity in the aftermath of an adverse shock by paying a lump-sum cost $T$ in the form of training. Then, the Bellman equations for each of the jobs become:

$$
\begin{aligned}
r J_{p}(z) & =y-w+\mu\left[\max \left\{J_{p}(z)-T, V_{p}-F\right\}-J_{p}(z)\right] \\
r J_{t}(z) & =y-w+\mu\left[\max \left\{J_{t}(z)-T, V_{t}\right\}+\alpha(F)\left[J_{p}(z)-J_{t}(z)\right]\right]
\end{aligned}
$$


Thus, under free entry, a firm with a permanent contract will undergo training if $J_{p}(z)>T-F$, while a firm with a temporary contract will not undergo training if $J_{t}(z)<T$. Given (A.3) (3) and (A.10), these conditions translate into the following inequalities:

$$
\begin{aligned}
T<T_{\text {upp }} & =\frac{y-w}{r+\mu}+\frac{r F}{r+\mu} \\
T>T_{\text {low }} & =\frac{(r+\mu)(1-\alpha(F))+\alpha(F)}{(r+\mu+\alpha(F))(r+\mu)}(y-w)-\frac{\alpha(F) \mu F}{r+\mu}
\end{aligned}
$$

where $T_{\text {upp }}$ and $T_{\text {low }}$ are upper and lower bounds for $T$, such that $T_{\text {low }}<T_{\text {upp }}$, and for $T_{\text {low }}<T<T_{\text {upp }}$ training only takes place in the submarket of permanent contracts.

The novel result in relation to Berton and Garibaldi (2012) is that, while $T_{u p p}$ increases with $F, T_{\text {low }}$ decreases. Thus, for given $T$, it is more likely that firms will only provide training to workers under permanent contracts in dual labor markets (where $F$ is large), than in more unified labor markets (where $F$ is smaller). This yields the main theoretical prediction to be tested in the empirical section.

\section{References}

Acemoglu D, Pischke J (1999) The structure of wages and investment in general training. J Polit Econ 107:539-572

Aguirregabiria V, Alonso-Borrego C (2014) Labor contracts and flexibility: evidence from a labor market reform in Spain. Econ Inq 52:930-957

Alba-Ramirez A (1994) Formal training, temporary contracts, productivity and wages in Spain. Oxf Bull Econ Stat 56:151-170

Amuedo-Dorantes C (2001) From “temp-to-perm" Promoting permanent employment in Spain. Int J Manpower 22:625-647

Amuedo-Dorantes C, Serrano-Padial R (2007) Wage growth implications of fixed-term employment: an analysis by contract duration and job mobility. Labour Econ 14:829-847

Arulampalam W, Booth AL, Bryan ML (2004) Training in Europe. J Eur Econ Assoc 2:346-360

Autor DH (2001) Why do temporary help firms provide free general skills training? Q J Econ 116:1409-1448

Autor DH, Houseman SN (2010) Do temporary-help jobs improve labor market outcomes for low-skilled workers? Evidence from "Work First". Appl Econ Am Econ J 2(3):96-128

Bassanini A, Booth A, Brunello G, De Paola M, Leuven E (2007) Training in the workplace. In: Brunello G, Garibaldi P, Wasmer E (eds) Education and training in Europe. Oxford University Press, Oxford

Bassanini A, Nunziata L, Venn D (2009) Job protection legislation and productivity growth in OECD countries. Econ Policy 24:349-402

Bentolila S, Cahuc P, Dolado JJ, Le Barbanchon T (2012) Two-tier labour markets in the Great Recession: France versus Spain*. Econ J 122:F155-F187

Berton F, Garibaldi P (2012) Workers and firms sorting into temporary jobs. Econ J 122:F125-F154

Boeri T, Garibaldi P, Moen E (2017) Inside severance pay. J. Pub Econ 145:211-225

Booth AL, Francesconi M, Frank J (2002) Temporary jobs: stepping stones or dead ends? Econ J 112(480):189-213

Cahuc P, Postel-Vinay F (2002) Temporary jobs, employment protection and labor market performance. Labour Econ 9:63-91

Ciccone A, Fontes WG (2008) The quality of the Catalan and Spanish education systems: a perspective form PISA. Universitàt Pompeu Fabra, Mimeo

De la Rica S, Dolado JJ, Llorens V (2008) Ceilings or floors? Gender wage gaps by education in Spain. J Popul Econ 21:751-776

Dearden L, Ferri J, Meghir C (2002) The effect of school quality on educational attainment and wages. Rev Econ Stat 84:1-20 
Dolado JJ, García-Serrano C, Jimeno JF (2002) Drawing lessons from the boom of temporary jobs in Spain. Econ J 112:F270-F295

Dolado JJ, Ortigueira S, Stucchi R (2016) Does dual employment protection affect TFP? Evidence from Spanish manufacturing firms. SERIEs 7:421-459

Eichhorst W (2013) The unequal distribution of labor market risks: permanent vs. temporary employment. IZA, http://www.iza.org/conference_files/EULaMaFuEm_2013/eichhorst_w2291.pdf

Fifth European Working Conditions Survey (2010) http://www.eurofound.europa.eu/surveys/ewcs/2010/. OECD, Paris

García-Pérez JI, Vall-Castelló J, Marinescu I (2016) Can fixed-term contracts put low skilled youth on a better career path?. Evidence from Spain, Technical report, National Bureau of Economic Research

Garda P (2012) Wage losses after displacement in Spain: the role of specific human capital. Universitat Pompeu Fabra (Mimeo)

Garriga C (2010) The role of construction in the housing boom and bust in Spain. In: Bentolila S, Boldrin M, Dolado J, Diaz-Gimenez J (eds) The crisis of the Spanish economy. Marcial Pons, Madird

Güell M, Petrongolo B (2007) How binding are legal limits? Transitions from temporary to permanent work in Spain. Labour Econ 14:153-183

Hall RE (2005) Employment fluctuations with equilibrium wage stickiness. Am Econ Rev 95:50-65

OECD (2013) Employment Protection Legislation, 2012-2013. OECD EPL database

OECD (2014) Employment outlook. Chapter 4: Non Regular Employment, Job Security and the Labour Market Divide. OECD, Paris

The European Commission (2014) EU skills panorama. European Commission, Brussels

\section{Publisher's Note}

Springer Nature remains neutral with regard to jurisdictional claims in published maps and institutional affiliations. 